\title{
INVESTIGATING THE THERMAL EFFICIENCY OF COMMERCIALLY AVAILABLE THERMO-FOILS IN SRI LANKA.
}

\section{ALAWATHTHAGE D. MADURANGA, H.H. SUMATHIPALA. AND N.W.K. JAYATISSA ${ }^{*}$}

\section{Department of Physics, University of Kelaniya, Kelaniya, Sri Lanka}

\begin{abstract}
The thermo-foil is an insulation material which can be used to insulate roofs of residential buildings which causes less energy to accomplish a comfortable temperature inside the building. It's becoming popular in Sri Lankan building construction sector. In this research, an investigation of the efficiency of the thermo-foils is done for commonly used brands. The important thermal properties are analyzed for thermo-foils with a thickness of $3 \mathrm{~mm}, 5 \mathrm{~mm}$ and $8 \mathrm{~mm}$ and it is tested using a miniature building model for the further evaluation of the efficiency. It was observed that the aluminium layer of the thermo-foil could reflect most of the radiation back and the polyethylene foam layer could keep a temperature gradient of a few degrees. A temperature drop of 1.6 to 2.8 degrees was noted. The results obtained were discussed with an analysis of the thermal insulation properties. A heat transfer model for a residential building was also proposed.
\end{abstract}

Keywords: Thermo - foils, Thermal conductivity, polyethylene foam, roof insulation

\section{INTRODUCTION}

Advancing to the modern world from the primitive eras, the human lifestyle has been changed and enormously developed. This growth towards the luxurious life was apparent in agriculture, manufacturing, production, and transportation etc. Henceforth, a rapid increment of energy consumption was apparent and caused "environment loading", the influence on the environment by human beings by means of emission of pollutants, use of resources, threats to the ecosystems and land use

\footnotetext{
${ }^{*}$ Corresponding author: Email: jayatissa @kln.ac.lk
} 
changes (Bueche, 1975). The comfort of the environment is affected by greenhouse gasses, responsible for global warming; hence the room temperature increases causing discomfort for the building occupants.

Thermal insulation is a method to reduce the heat transfer of the building. An insulated house is more comfortable as the temperature remains consistent over weather changes such as rising daytime temperature (Lux and Ray, 1970). Thermal insulation of exposed roofs is a very effective method for a country like Sri Lanka near equator as the solar radiation incidents throughout the year and roof is the main surface which absorbs and conducts heat into the building. Employing an insulation material, the heat transfer can be controlled to attain a comfortable environment inside the building.

Thermo-foils which are widely used in roof insulation can be identified by different names such as heat foils, aluminium foils, roofing foils etc. Generally, thermo-foil is a polyurethane or polyethylene foam layer of various thicknesses (3 -12 $\mathrm{mm}$ ) with a reflecting thin aluminum layer. The aluminium layer helps to have a shiny look and a corrugated surface to the thermo-foil.

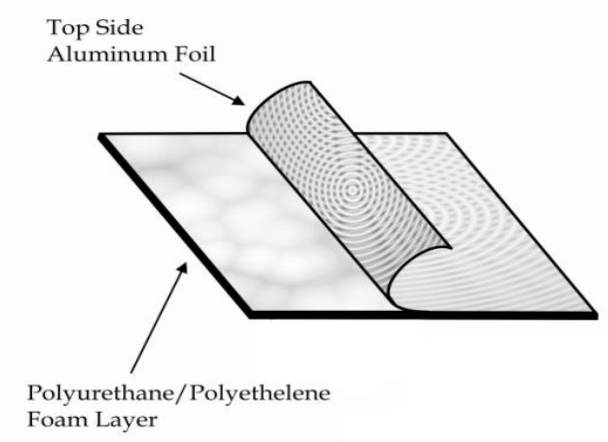

Figure 1: Structure of the Thermo-foil

The top layer of the thermo-foil is an aluminium foil which is made by an aluminium alloy that contains $92-94$ percentage of aluminium (called aluminum in America). It is used to manufacture thermal insulation for the construction industry, fin-stock for air conditioners, electrical coils for transformers, capacitors for radios and televisions, insulation for storage tanks, decorative products containers and packaging.

The polyethylene foam layer of the thermo-foil holds a significant importance in resisting the heat flow through it. The thermo-foils with different thicknesses of the 
polyethylene layer are available in the market. Polyethylene foam as a porous material has an irregular inner geometric structure. Polyethylene or polythene which has the IUPAC name polyethene or poly (methylene) is a thermoplastic commodity heavily used in consumer products. The polyethylene foam has the following properties as specified in the manufacturer datasheets.

\section{Table 1: Properties of Polyethylene foam layer}

\begin{tabular}{lc}
\hline Material property & Value \\
\hline Apparent Density $\left(\mathrm{gcm}^{-3}\right)$ & 0.033 \\
Tensile strength $\left(\mathrm{kgcm}^{-1}\right)$ & 3.4 \\
Elongation to break $(\%)$ & 140 \\
Thermal conductivity $\left(\mathrm{Wm}^{-1} \mathrm{~K}^{-1}\right)$ & 0.0383 \\
Compression strength $\left(\mathrm{kgcm}^{-1}\right)$ & 0.197 \\
Operating temperature $\left({ }^{\circ} \mathrm{C}\right)$ & -80 to +80 \\
Water Absorption $\left(\mathrm{mg} / \mathrm{cm}^{3}\right)$ & 0.03 \\
\hline
\end{tabular}

Whenever a temperature difference exists, there exists a tendency to transfer heat. The amount of heat transferred is a function of the temperature difference and of the resistance in the heat-transfer path. When the radiation heat incidents on the roof, the aluminium layer reflects some portion of the radiation while absorbing some of the radiation (heat energy) which increase the temperature of the roof. The absorbed heat is then transferred through the roofing material into the building. When the thermo-foil is inserted in between the roofing material and the building interior, it is apparently working as a barrier to the heat transmission. These resistance properties of the thermofoil are analyzed experimentally.

\section{MATERIALS AND METHODS}

The radiation energy received by a surface can be explained by an equation as follows (Doolittle, 1960; Giancoli, 1998):

$$
\alpha+\rho+\tau=1
$$

Where $\alpha$ is the absorptivity or the portion of the radian energy which is absorbed, $\rho$ is the reflectivity, or the portion of the radiant energy which is reflected 
and $\tau$ is the transmissivity, or the portion of the radiant energy which is transmitted (Doolittle, 1960; Giancoli, 1998).

A black surface has a higher value for absorptivity which is close to unity. For this reason the term black body has been used to designate an imaginary object whose surface has an absorptivity of unity. For aluminium surface of the thermo-foil, the transmissivity can be considered as zero. Then the equation can be rearranged as

$$
\alpha+\rho=1
$$

Emissivity is the amount of heat a body looses in forms of radiation. Emissivity of a surface at any temperature equals to its absorptivity of radiant energy from a surface at the same temperature (Doolittle, 1960; Giancoli, 1998).

Fourier's law of heat conduction can be written as follows (Giancoli, 1998), where $\mathrm{k}$ is the thermal conductivity of the material and the thermal resistance of the material is given by (04) where, $\mathrm{X}$ is the thickness of the material (Doolittle, 1960; Giancoli, 1998).

$$
\begin{aligned}
& \frac{d Q}{d t}=-k A \frac{d T}{d x} \\
& R=X / k
\end{aligned}
$$

\section{(i) Reflection Measurement}

The aluminium layer of the thermo-foil was subjected to the heat reflection measurement. A prism table was taken as the basic setup for the reflection measurement, having the collimator adjusted so that it could give a light spot on the material sample having a radius of $1-2$ centimeters. The telescope of the prism table was replaced by the light sensor probe of the "Lab Pro" experimental interface. The reflected light from the thermo-foil was detected through the applicable range when the thermo-foil was fixed on the prism table making an angle with the incoming light beam. The reflection data was recorded for the horizontal and vertical orientations of the corrugated pattern with respect to the prism table and incoming beam. The procedure was repeated for a sample Asbestos ceiling sheet and a mirror plate to infer a proper comparison. 


\section{(ii) Heat Resistance Measurement}

The porous foam layer of the thermo-foil was subjected to the heat resistance measurement, using the Lee's disk method, which is for measuring the thermal conductivity of poor conducting materials. The thermo-foil was clamped to the apparatus such that it has a good thermal contact with the disks and without a deformation to its shape and dimensions. At the steady state of the heat flow through the thermo-foil, the thermometer readings were noted down. This was repeated for the thermo-foils with different thicknesses which are available in the market.

\section{(iii) Testing Thermo-foil with Building Models}

The ability of the thermo-foil to minimize the heat transfer into the building is tested as a whole using some scale down building models (about 3.5 cubic feet), each model having the same dimensions, appearance and properties. The roof of a model, made of Asbestos ceiling sheets, was insulated with a thermo-foil having an air gap between the roof and it about $5 \mathrm{~mm}$ and the shiny aluminum layer facing the roof. The walls of the models are being made with thin wooden boards. Another similar model was taken as the control experiment without installing the thermo-foil.

The two models were placed in a lawn such that the shadows do not interfere while the experiment was being done. The models were placed on a wooden surface about 1 meter above the ground, so as to keep the surrounding environment of the models similar. The ambient temperature, thermometer and thermocouple readings of the control model and that of the foiled model were noted down with the passing time. The procedure was repeated for the thermo-foils with different thicknesses which are available in the market.

\section{RESULTS AND DISCUSSION}

The aluminium layer of the thermo-foil is participating for the reflection of the incident beam. The surface of the thermo-foil and the aluminum layer has a corrugated nature. Reflection spectra for the two orientations of the corrugated pattern, horizontal and vertical, are plotted in the same graph. While the mirror plate reflects the incident beam as an exact spot without scattering the beam, the thermo-foil scatters the incoming radiation into all possible directions (Figure 2 and Figure 3). 


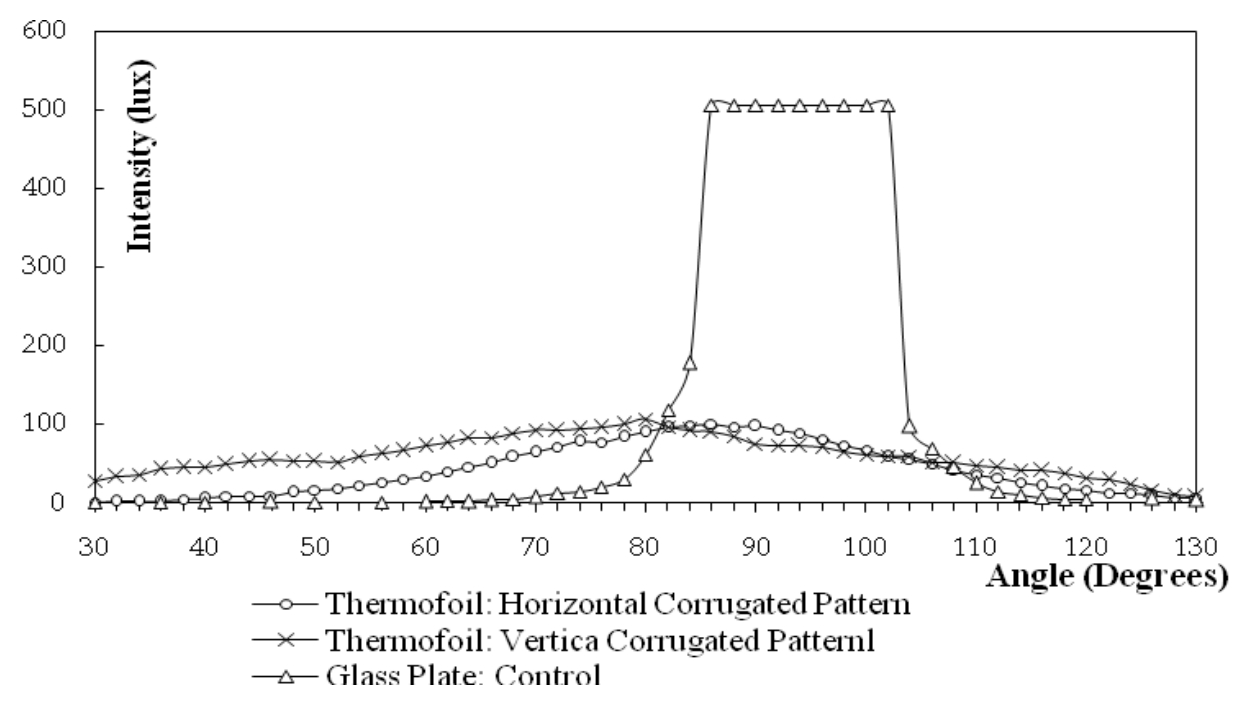

Figure 2: The Graph of Intensity Vs Angle for Thermo-foil

The asbestos sheet does not properly reflect the incident beam as the thermofoil. It demonstrates a flat curve with respect to the thermo-foil.

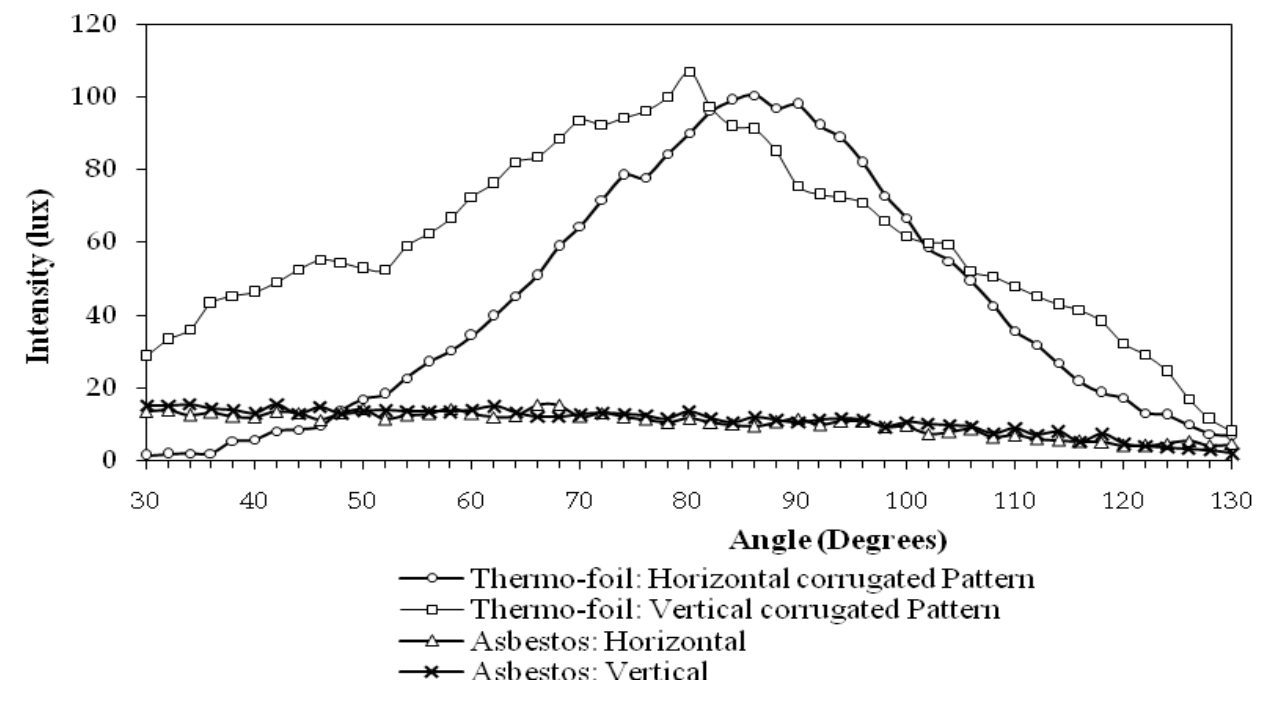

Figure 3: The Graph of Intensity Vs Angle for Thermo-foil

The curves of the thermo-foil approximately obey the Gaussian distribution. The cumulative intensity that the asbestos sheet reflects is 2153 lux which is $20.16 \%$ of the 
reflection of the mirror plate. The Cumulative sum of the reflection of the thermo-foil is 10449 lux which is $97.8 \%$ of the mirror plate (10680 lux). This illustrates that, according to the Figure 2, the asbestos sheet absorbs more radiation and heat than it reflects. In contrast, the thermo-foil reflects more heat than it absorbs.

The efficiency of the polyethylene foam layer is its ability to resist the heat transfer through it. The polyethylene layer is a porous medium with irregular inner structure. The tiny bubbles inside the material are filled with air, disturbing the proper heat transfer by means of conduction. Therefore the heat transfer through this layer will occur by both conduction and convection and a large experimental process with assumptions should be taken place to estimate the effective thermal conductivity (Mingheng et al., 2008).

As specified by the manufacture (whose products which were used in the experiment), the thermal conductivity of the thermo-foil was about $0.0384 \mathrm{Wm}^{-1} \mathrm{~K}^{-1}$. Three thermo-foil samples with three different thicknesses were tested for their heat resistance properties.

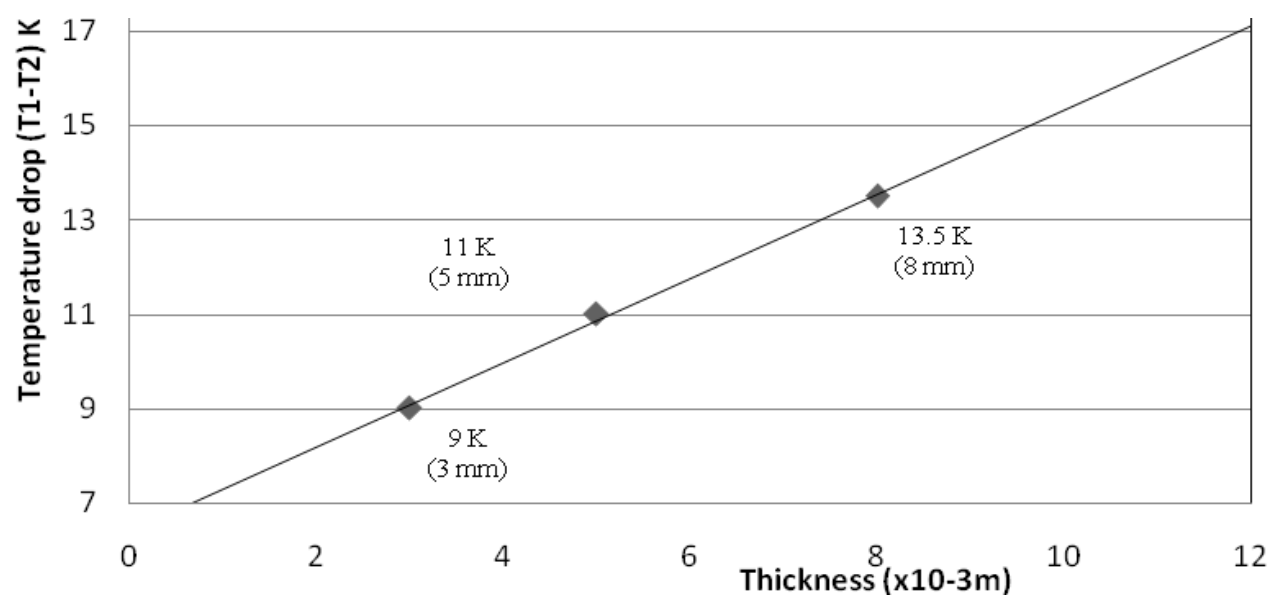

Figure 4: Temperature drop vs. thickness of the foil

The temperature drop through thermo-foil increases with the thickness (Figure 4). The two surfaces of the thermo-foil that touches the brass disks (one end there lies the heat dissipater) maintains a temperature gradient of 9 Kelvin degrees when the thickness is $3 \mathrm{~mm}$ and 11 Kelvin degrees when the thickness is $5 \mathrm{~mm}$. Proving that the 
temperature drop that can be attained by the thicker foils will be higher, the $8 \mathrm{~mm}$ thick foil holds a temperature gradient of $13.5 \mathrm{~K}$.

A thermo-foil with a thickness of $3 \mathrm{~mm}$ was tested as described in the section (III) in the materials and methods. It is clearly seen that the temperature inside the building holds a lower value than the temperature inside the control (Figure 5).

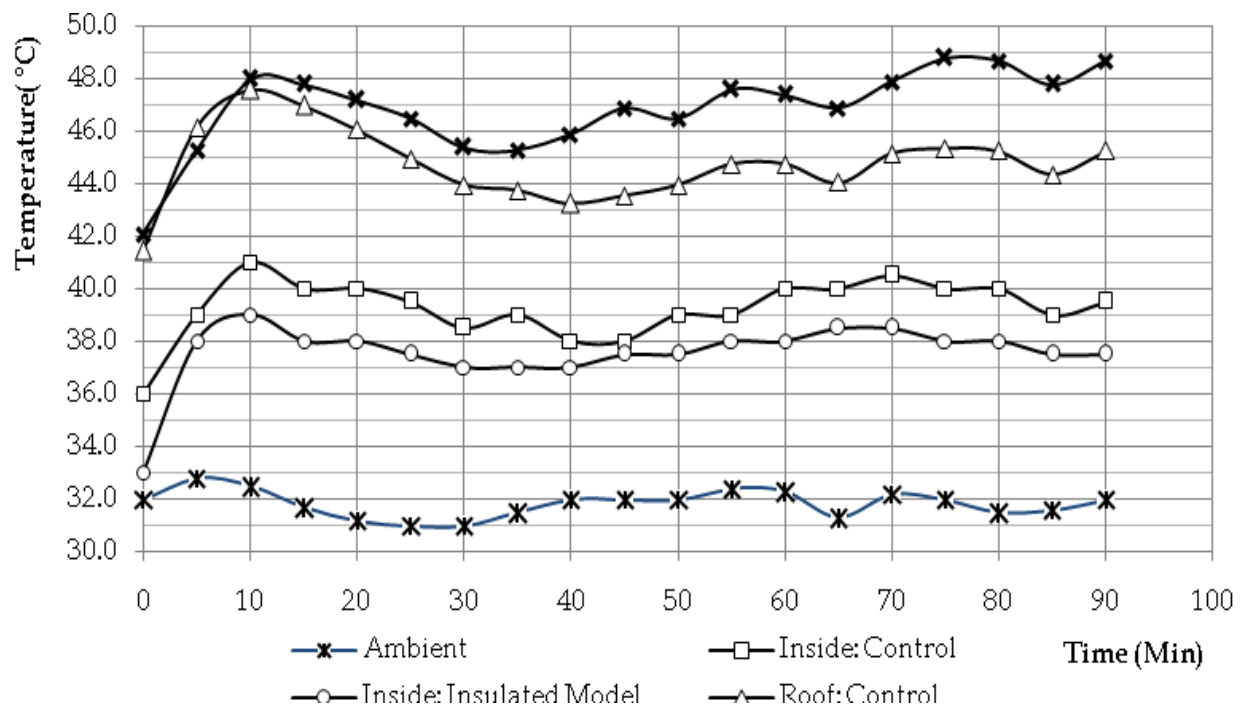

Figure 5: The temperature variation with the time for two building models ( $3 \mathrm{~mm}$ thermo-foil)

The temperature at the roof of the control holds a lower value and the temperature in the air gap in between the roof and the thermo-foil holds a much larger value. This is because the heat circulates in the air gap as the thermo-foil resists the heat to transfer through it.

The average values of temperature variation inside the two building models can be compared together as follows (Figure 6). 


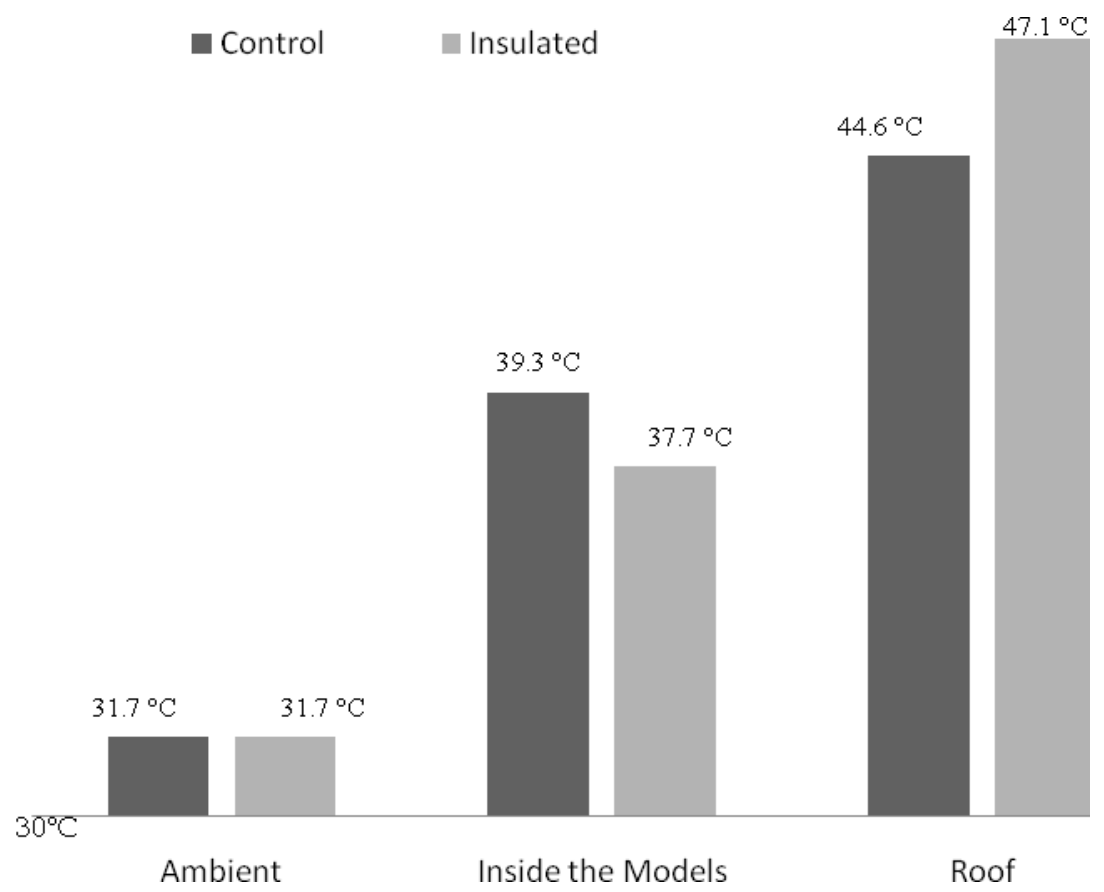

Figure 6: Average temperature values (Insulated with $3 \mathrm{~mm}$ thermo-foil)

The average temperature drop inside the building when the roof is insulated by $3 \mathrm{~mm}$ thermo-foil is $1.6^{\circ} \mathrm{C}$ (Figure 6). The Temperature difference between the inner side of the roof of the control and the air gap of the insulated model is $2.5^{\circ} \mathrm{C}$.

The thermo-foil with a thickness of $8 \mathrm{~mm}$ was tested using the same experimental procedure as described in the section (III). The temperature variation was plotted (Figure 7). The pattern of the temperature curve shows consistency with the temperature variation of the Figure 5. Instead of a rapid variation, the temperature inside the insulated illustrates a stable temperature variation with the control model.

The average values of temperature variation inside the two building models can be compared together as follows (Figure 7). The calculated average interior temperature drop is $2.8^{\circ} \mathrm{C}$ while the Temperature difference between the inner side of the roof of the control and the air gap of the insulated model is $2.8^{\circ} \mathrm{C}$.

It can be observed in Figures 5 and 6 that the ambient temperature of Figure 5 shows a slight drop by several degrees than in the Figure 6. This is because the days on 
which this experiment for $8 \mathrm{~mm}$ thermo-foil was performed were cloudy and wet comparing to the previous.

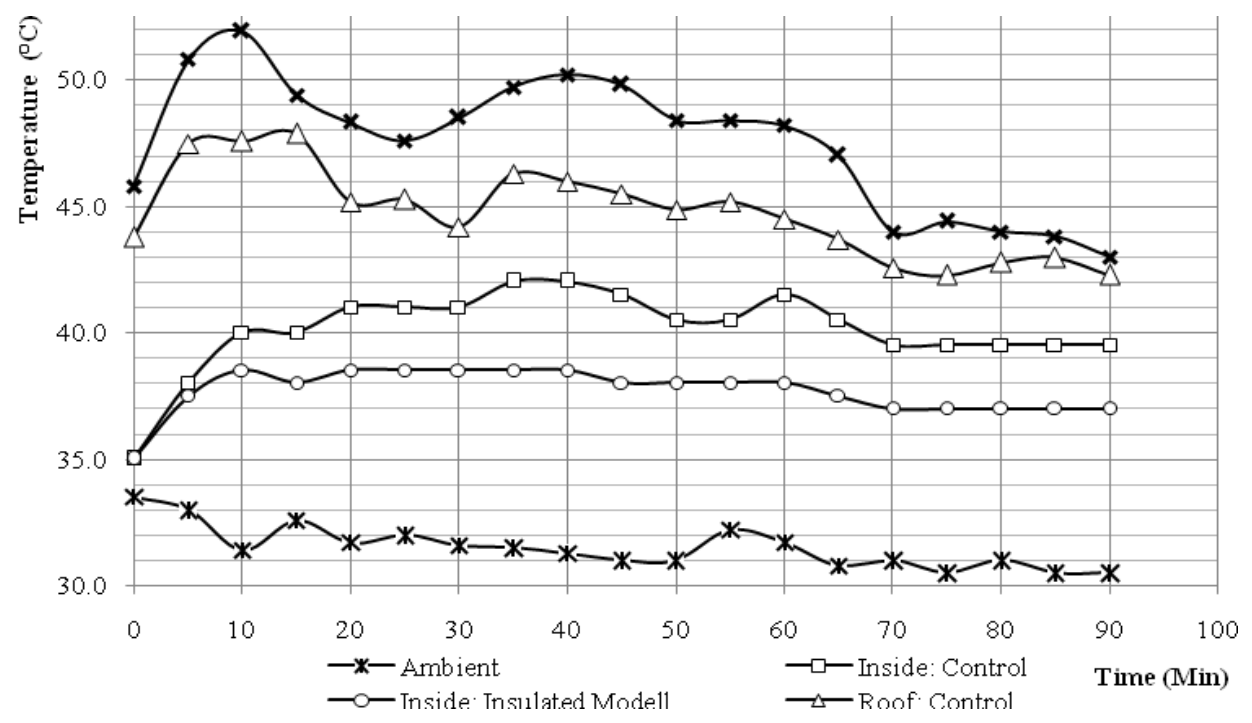

Figure 7: The temperature variation with the time for two building models (8 $\mathrm{mm}$ thermo-foil)

- Control Insulated

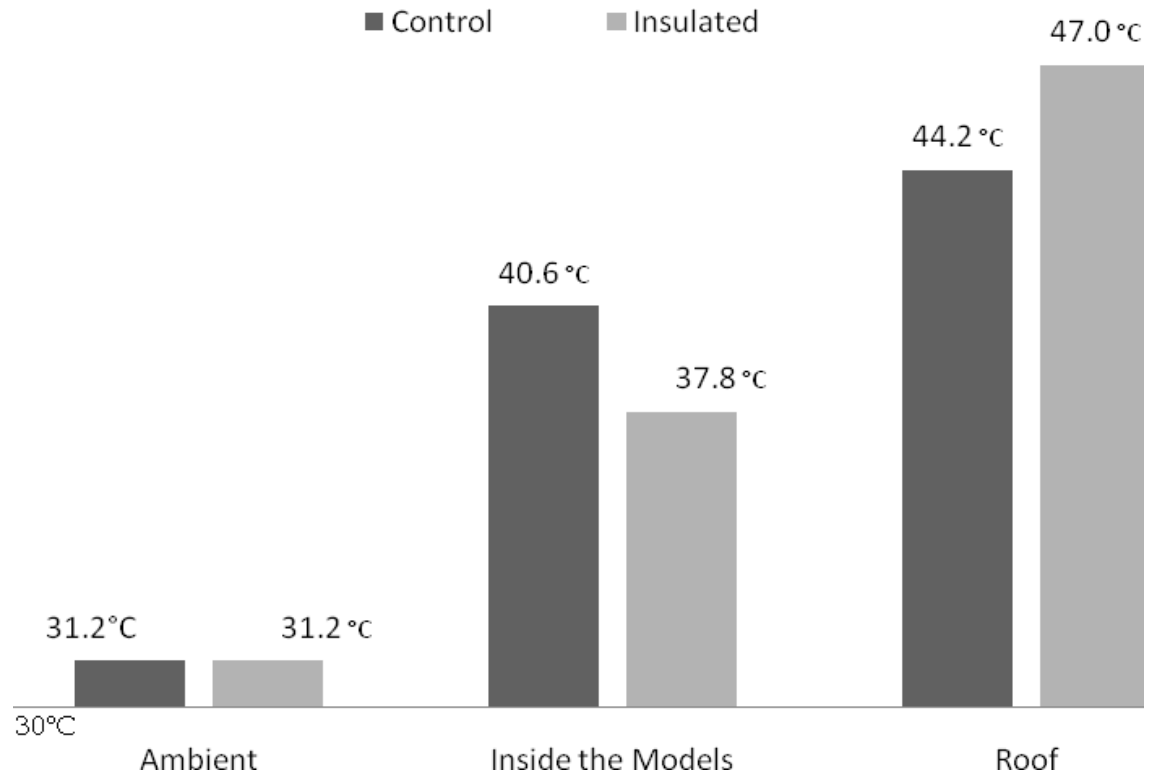

Figure 8: Average temperature values (Insulated with $8 \mathrm{~mm}$ thermo-foil) 
In summary, when the thermo-foils are tested with the scale-down building models a drop of 1.6 degrees attained by the $3 \mathrm{~mm}$ thick foil while 2.8 degrees dropped by the foil having a thickness of $8 \mathrm{~mm}$, which may depend on the size of the building model. The drop in temperature is not proportional to the increase in thickness.

\section{Table 2: Temperature drop due to two different thicknesses of the thermo-foil}

\begin{tabular}{cccc}
\hline $\begin{array}{c}\text { Thickness } \\
\left(\mathbf{x 1 0 ^ { - 3 }} \mathbf{m}\right)\end{array}$ & $\begin{array}{c}\text { Average Temperature } \\
\text { Drop }\left({ }^{\circ} \mathbf{C}\right)\end{array}$ & $\begin{array}{c}\text { Variation } \\
\left(\boldsymbol{\sigma}^{\mathbf{2}}\right)\end{array}$ & $\begin{array}{c}\text { Standard Deviation } \\
(\boldsymbol{\sigma})\end{array}$ \\
\hline 3 & 1.6 & 0.22 & 0.47 \\
8 & 2.8 & 0.19 & 0.44 \\
\hline
\end{tabular}

\section{Proposed heat transfer model}

The radiation energy incoming from the sun is absorbed by the asbestos sheet (roof) and it emits the heat energy as radiation back to the atmosphere and building interior when the thermo-foil is not installed (control). Therefore the temperature inside the building rises. Nevertheless, when the thermo-foil is applied, that radiation is blocked by the aluminium layer and is reflected back scattering it so that the roof is heated and the convection currents deliver that heat into the air gap between the roofing sheet and the thermo-foil. The oscillation of this radiation and convection heat increases the temperature of the air gap to a considerable high value compared to the same point at the control model.

The heat absorbed by the thermo-foil after all is transferred through the polyethylene foam layer of the thermo-foil. The porous irregular inner structure of the thermo-foil resists the heat transfer through the foil as it does not allow the heat to transfer properly. The heat is transferred into the building by means of radiation from the bottom surface of the thermo-foil and convection currents can help cooling the thermo-foil. Heat losses to the atmosphere keep the system in equilibrium.

\section{CONCLUSIONS}

There are two major characteristics that the thermo-foil has which minimizes the heat transfer into the residential building. A high reflective aluminium layer works as a barrier to the radiant heat and reflects back $97.8 \%$ of the radiant heat. Heat resistive polyethylene layer which has a very low thermal conductivity value 
$\left(0.383 \mathrm{Wm}^{-1} \mathrm{~K}^{-1}\right.$ according to the manufacturer) minimizes the heat absorbed by the aluminium layer being transferred into the building. The temperature gradient by the polyethylene foam layer under the Lee's disk method increase with the thickness and it was 13.5 degrees Celsius for the $8 \mathrm{~mm}$ foil.

The temperature drop inside a building due to the thermo-foil increases with its thickness. Considering the insulated miniature building model, a temperature drop of 1.6 degrees could be observed for the $3 \mathrm{~mm}$ thick foil. When the roof was insulated with $8 \mathrm{~mm}$ thick foil, the temperature drop was 2.8 degrees. These values may differ from the real world buildings. However if the building is air-conditioned, the drop of the temperature by couple of degrees will reduce the cooling load of the airconditioners and therefore a significant amount of energy saving will be possibly experienced.

\section{REFERENCES}

Bueche, F.J. 1975. Introduction to Physics for scientists and engineers. McGraw-Hill Education, Maidenhead, UK.

Doolittle, J.S. 1960. Thermodynamics for engineers. 2nd edition. International Textbook Company, Scranton, Pennsylvania, USA.

Giancoli, D.C. 1998. Physics - Principles with applications. 5th edition. Prentice Hall, Englewood Cliffs, New Jersey.

Lux, D.G. and W. E. Ray 1970. The world of construction. $4^{\text {th }}$ edition. McKnight \& McKnight Publishing Company, Illinois, USA.

Mingheng, S. X. Li and Y. Chen 2008. Determination of effective thermal conductivity for polyurethane foam by use of fractal method. Southeast University, Nanjing, China. 